\section{$\omega$-Helix in Synthetic Polypeptides}

IT is now well established that in the solid state many preparations of synthetic polypeptides form stable helical structures which correspond closely to the $\alpha$-helix described by Pauling, Corey and Branson ${ }^{1}$. With other preparations, however, the $\alpha$-helical configuration appears to be less stable, apparently due either to a low degree of polymerization ${ }^{2}$ or to the nature of the side-chain ${ }^{3}$. In the case of poly- $\beta$ benzyl-L-aspartate ${ }^{4,5}$ steric interference between the side-chain and main-chain renders the $\alpha$-helical configuration comparatively unstable, and on heating films in vacuo the molecules adopt a new helical form resembling the $4_{13}$ configuration described by Bragg, Kendrew and Perutz ${ }^{6}$. The new configuration, which has been termed the $\omega$-helix, has a pitch of $5 \cdot 30 \AA$. with four residues per turn and is believed to be of opposite screw sense to the $\alpha$-helix. We are at present investigating synthetic polypeptides with side-chains which are derivatives of cysteine and wish to report the discovery of a second example of a four residue per turn helix which closely resembles, but is not identical with, that found in poly- $\beta$-benzyl- $\mathrm{L}$-aspartate.

The polymer poly- $S$-benzylthio-L-cysteine was synthesized in methylene chloride from the corresponding $N$-carboxyanhydride, the preparation of which will be described in detail elsewhere. No solvents for this polymer have so far been found, but thin films showing a high degree of planar orientation were recovered from the walls of the polymerization vessel. On rolling, a considerable degree of uniaxial orientation was obtained and the films yielded sharp $\mathrm{X}$-ray reflexions indicating a high degree of crystallinity. Four well-developed layer lines were observed and the spacings for the equator and first layer line are given in Table 1 . It will be seen that the reflexions may be indexed on a tetragonal cell with $a=$ $14.28 \AA$. and $c=5.55 \AA$. The tetragonal symmetry, together with the absence of meridional reflexions except on the fourth layer line, strongly suggest that the polymer has a helical configuration with four residues per turn and a pitch of $5 \cdot 55 \AA$. From density considerations there can only be one polymer chain passing through the unit cell so that the space group is $P 4_{1}$ or $P 4_{3}$ depending on the screw sense of the helix.

The helix is thus not identical with that in the aspartate polymer as the pitch is $5.55 \AA$. rather than $5 \cdot 30 \AA$. (cf. $\alpha$-helix $5 \cdot 4 \AA$.); but it is convenient to retain the term $\omega$ to describe it. In contrast to the

Table 1. PoLY-S-BenzyLthio-L-Cysteine

Observed $\left(d_{0}\right)$ and calculated $\left(d_{c}\right)$ spacings $(\AA$.$) based on a tetragonal$ cell with $a=14.28 \AA$.; $c=5.55 \AA$. Space group $P 4_{1}$ or $P 4_{3}$

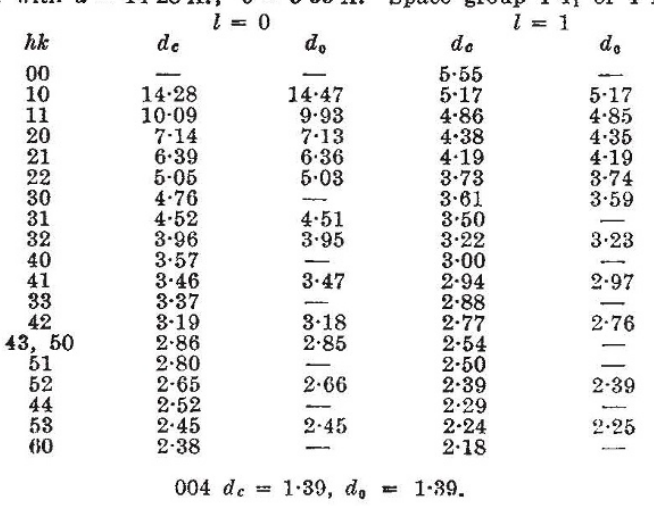

conclusions of Blout et al. ${ }^{3}$, we believe that the comparative instability of the $\alpha$-helix in polycysteine derivatives is to be explained in terms of steric interference between the sulphur atom of the sidechain and the main-chain atoms. In conclusion, it is interesting to note that the number of atoms between the $\alpha$-carbon and the benzene ring in poly-S-benzylthio-x-cysteine:<smiles>CCCCCCCCCSSCC1CCCC1</smiles>

is the same as that in poly- $\beta$-benzyl-L-aspartate:<smiles>O=C(CC1NCCO1)OCc1ccccc1</smiles>

and this may be a prerequisite for the formation of the $\omega$-helix. In contrast poly-S-benzyl-L-cysteine:<smiles>CCCCCCCCSCC1NCCO1</smiles>

yields only a poorly crystalline $\alpha$-helix X-ray pattern under the same conditions of preparation.

\section{R. D. B. Fraser \\ T. P. MAcRAF \\ I. W. Staplfton}

Division of Protein Chemistry,

Commonwealth Scientific and Industrial Research Organization,

Wool Research Laboratories,

Parkville, N.2, Victoria, Australia.

' Pauling, L., Corey, R. B., and Branson, H. R., Proc. O.S. Nat. Acad. Sci., 37, 205 (1951).

${ }^{2}$ Bradbury, E. M., Brown, L., Downie, A. R., Elliott, A., Fraser, R. D. B., Hanby, W.'E., and MeDonald, T. R., J. Mol. Biol., 2, $276(1960)$.

${ }^{3}$ Blout, E. R., de Lozé, C., Bloom, S. M., and Fasman, G. D., J. Amer. Chem. Soc., 82, 3787 (1960).

- Bradbury, E. M., Brown, L., Downie, A. R., Elliott, A., Hanby, W. E., and MeDonald, T. R. R., Nature, 183, 1736 (1959).

- Bradbury, E. M., Brown, L., Downie, A. R., Elliott, A., Fraser, Hanby, W. E., Mol, Biol. (in the press).

- Bragg, W. L., Kendrew, J. C., and Perutz, M. F., Proc. Roy. Soc. A 203, $321(1950)$

\section{Labile Organo-Halogen Compounds and their Gas Chromatographic Detection and Determination in Biological Media}

THE great usefulness of DDT and similar organochlorine pesticides to agriculture and for the preservation of health throughout the world has lead to an enormous distribution of these chemicals. For example, the production in 1959 for DDT in the United States was $156,738,000$ lb. ${ }^{1}$. The ultimate fate of this enormous tonnage in relation to food consumption and to physiological effects on man and animals is a matter that merits and receives considerable scientific investigation.

In order to develop useful, rapid, and accurate means of segregating DDT and similar residues from 